\title{
Erosión dental a causa de diversos jugos de frutas naturales
}

\author{
Tooth erosion from various natural fruit juices
}

\author{
María Valeria Sihuay Torres ${ }^{1, a}$, Lidia Giovanna Montes Manrique 1,a, \\ Carmen Fiorella Rodríguez Sánchez ${ }^{1, a}$.
}

\section{Sr. Editor:}

Hemos leído con gran interés el artículo titulado "Potencial erosivo de jugos de frutas amazónicas" publicado en la Revista Estomatológica Herediana (1), el cual consideramos relevante debido a que indica que estas bebidas son altamente erosivas. Queremos resaltar el método de investigación que se utilizó en dicho trabajo, y la importancia de realizar estudios similares para crear mayor conciencia en la sociedad. Por ello, el objetivo de esta carta es reforzar las recomendaciones que se hicieron, ya que, actualmente, se observa un incremento en el consumo de este tipo de bebidas porque se cree que pueden prevenir la COVID-19.

La erosión dental se define como la pérdida química de la superficie del esmalte por una exposición repetida de ácidos de origen no bacteriano (1). De acuerdo a su origen, puede ser de dos tipos: intrínseca y extrínseca; la primera se produce a causa de reflujos gastroesofágicos, vómitos recurrentes o regurgitación, y la erosión extrínseca, por otro lado, se asocia al consumo de alimentos o bebidas ácidas, por ejemplo, los jugos de frutas, gaseosas, entre otros. Clínicamente, la erosión dental extrínseca se manifiesta con decoloraciones por exposición de dentina en la zona vestibular de los dientes, esto además, origina dolor debido a los cambios térmicos y a la masticación (2).

Cabe resaltar que estas lesiones están relacionadas con la ingesta de bebidas no carbonatadas como los jugos de frutas (3); estos jugos tienen una gran cantidad de ácidos orgánicos con un $\mathrm{pH}$ muy bajo, por ejemplo, el ácido tartárico, cítrico, maleico y ascórbico; los cuales están presentes en las uvas, naranjas y manzanas respectivamente (4). Todos estos ácidos producen la disolución de la apatita de los dientes por su alto potencial erosivo (5). Incluso, muchas personas las consideran "bebidas saludables", y que les ayudará a prevenir ciertas enfermedades, ya que son una gran fuente de vitamina C (6); hasta se ha llegado a creer que pueden mejorar el sistema inmune para prevenir enfermedades como la COVID-19 (7).

Sin embargo, se ha demostrado que diferentes frutas amazónicas y/o tropicales son causantes de la erosión dental; algunas de estas son el camu camu (Myrciaria Dubia), copoazú (Theobroma grandiflorum), la guanábana (Annona muricata), jobo (Spondias mombin), umbú (Spondias tuberosa), mango verde 
(Mangifera indica), lima (Citrus aurantiifolia) tamarindo (Tamarindus indica), carambola (Averrhoa carambola) y aguaymanto (Physalis Peruviana) $(1,3)$. Así mismo, se ha demostrado que el jugo de uvas es más erosivo que el jugo de naranja (8). Debemos tener en cuenta que el potencial erosivo de los jugos no sólo depende de su acidez, sino también de las características inherentes de las personas. Por ejemplo, la capacidad buffer y el flujo salival, así como la formación de la película adquirida (9).

Es importante que dentro de la anamnesis que le hace el odontólogo al paciente, le haga preguntas sobre su alimentación, el tipo de bebidas que consume y si sufre de reflujo gastroesofágico. También se debe indagar si el paciente aprieta los dientes de forma habitual o al dormir. Si el paciente informa que no sufre de reflujo gastroesofágico, ni apretamiento dental, pero si consume habitualmente bebidas gaseosas o jugos de frutas a base de limón, uva, naranja, lima, entre otros; se podría confirmar el diagnóstico de erosión dental de origen extrínseco. En estos casos, los malos hábitos dietéticos juegan un factor de riesgo importante (10).

Como tratamiento, se deben modificar los hábitos alimenticios, reduciendo el consumo de alimentos ácidos y evitando las bebidas gaseosas. En cuanto a los hábitos de higiene, se recomienda usar pasta con más de 1450 ppm de flúor y un cepillo de cerdas suaves para minimizar cualquier desgaste adicional de los dientes. Es importante resaltar que la higiene bucal después de consumir este tipo de bebidas debe ser por lo menos a los 30 minutos. Esta recomendación se da para la higiene bucal en general, sin embargo, el consumo de estas bebidas aumenta significativamente la acidez en boca lo que podría ocasionar lesiones abrasivas en los dientes (9).

Para finalizar, creemos que es necesario concientizar a la población sobre el efecto erosivo dental de los diversos jugos naturales a base de frutas tropicales. Además, el odontólogo debe reforzar esta idea en sus pacientes y realizar un adecuado diagnóstico de este tipo de lesiones. Esto se logrará haciendo una correcta anamnesis, para identificar las principales causas del problema y así poder brindar el mejor tratamiento e información sobre las medidas preventivas ante estas situaciones.

\section{Correspondencia:}

Maria Valeria Sihuay Torres.

Marcelino Varela 378 los ficus Santa Anita, lima, Perú Correo electrónico: vale.sihuay@gmail.com.

\section{REFERENCIAS BIBLIOGRÁFICAS}

1. Acuña S, Tay-Chu L, Ccahuana-Vasquez R, DelgadoCotrina L. Potencial erosivo de jugos de frutas amazónicas. Rev. Estomatol Herediana. 2020;30(3):187-95. DOI: https://doi.org/10.20453/reh. v30i3.3821

2. Mafla AC, Cerón-Bastidas XA, Munoz-Ceballos ME, Vallejo-Bravo DC, Fajardo-Santacruz MC. Prevalence and Extrinsic Risk Factors for Dental Erosion in Adolescents. Journal of Clinical Pediatric Dentistry [Internet]. 2017;41(2):102-11.

3. De Paula R, De Souza R. Ferreira I, et al. Ex Vivo Evaluation of the Erosive Potential of Typical Fruit Juices from Brazilian Tropical Forests. J Clin DiagnRes. 2019; 13 (7):36-40.

4. Ekfeldt A, Carlsson GE. Dental status and oral function in an adult group of subjects with thalidomide embryopathy - a clinical and questionnaire study. Acta Odontol Scand. 2008; 66: 300-306.

5. Beltrame APCA, Noschang RAT, Lacerda DP, Souza LC, Almeida ICS. Are grape juices more erosive than orange juices? Eur Arch Paediatr Dent. 2017;18(4):26370 .

6. Steiger-Ronay V, Stelz S, Steigmeier D, Becker K, Wiedemeier D, Attin T. Change of erosive potential of apple and orange juice at different dilutions. Swiss Dental Journal Sso. 2020; 130:12-7.

7. Mendez D, Padilla P, Lanza S. Recomendaciones alimentarias y nutricionales para la buena salud durante el COVID-19. INNOVARE. 2020; 9(1):55-7.

8. Kijsamanmith K, Surarit R, Vongsavan N. Effect of tropical fruit juices on dentine permeability and erosive ability in removing the smear layer: An in vitro study. $\mathrm{J}$ Dent Sci. 2016;11(2):130-5.

9. Zero DT, Lussi A. Erosion - chemical and biological factors of importance to the dental practitioner. Int Dent J. 2005; 55(4):285-89.

10. Fernández C, Marchena L, García B. Erosión dental: caso clínico. REDOE. 2014 (Consultado el 24 de diciembre del 2020). Disponible en: http://www.redoe. com/print.php?id=156. 